\title{
Sparing internal thoracic vessels in thoracoscopic or submuscular correction of pectus carinatum: A porcine model study
}

\author{
Ruben Lamas-Pinheiro ${ }^{\mathrm{a}, \mathrm{b}, \mathrm{c}}$, Francesca Mitzman ${ }^{\mathrm{a}, \mathrm{b}}$, Alice Miranda ${ }^{\mathrm{a}, \mathrm{b}}$, Tiago Henriques-Coelho ${ }^{\mathrm{c}}$, \\ José Estevão-Costa ${ }^{\mathrm{c}}$, Jorge Correia-Pinto ${ }^{\mathrm{a}, \mathrm{b}, \mathrm{d}, *}$ \\ a Life and Health Sciences Research Institute (ICVS), School of Health Sciences, University of Minho, Braga, Portugal \\ b ICVS/3B's-PT Government Associate Laboratory, Braga/Guimarães, Portugal \\ c Pediatric Surgery Department, Hospital São João, Faculty of Medicine, Porto, Portugal \\ d Pediatric Surgery Department, Hospital de Braga, Braga, Portugal
}

\section{A R T I C L E I N F O}

\section{Article history:}

Received 12 May 2015

Received in revised form 8 July 2015

Accepted 26 July 2015

Available online $\mathrm{xxxx}$

\section{Key words:}

Chest wall deformities

Pectus carinatum

Minimally invasive surgery

Thoracoscopy

Endoscopy

\begin{abstract}
A B S T R A C T
Background: External compression is used for pectus carinatum (PC) treatment, but many patients are noncompliant. Costal cartilage resection (CCR) has been described as an alternative, but these approaches sacrifice the internal thoracic arteries (ITA). We aim to assess the feasibility of CCR sparing ITA comparing thoracoscopic and subcutaneous endoscopic approaches.

Methods: Twelve pigs were used as models for surgical PC correction and randomized for 2 groups: thoracoscopy (T) and subcutaneous (subpectoralis) endoscopy (SP). In both groups, CCR from 3rd 4th and 5th ribs was performed avoiding ITA damage. ITA preservation was confirmed by Doppler-ultrasound as well as postmortem injection of methylene blue. Four persons evaluated the procedures being difficult, using a 6-item modified validated scale.

Results: In both techniques, the procedure was accomplished in all animals sparing ITAs. CCR was faster in T than in SP $(49 \pm 5$ vs. $65 \pm 16$ minutes, $p<0.05)$. T was classified as easier than SP $(p<0.001)$ with a significantly higher score for all items, especially better image and tissue handling.

Discussion: Sparing the ITAs during CCR for correction of PC is feasible in a porcine model and might be a goal in humans. The thoracoscopic approach allows for a faster and easier procedure.
\end{abstract}

(c) 2015 Elsevier Inc. All rights reserved.
Pectus carinatum (PC) is defined as the protrusion of the sternum or the ribs. The overall prevalence is around $0.6 \%$ being the second most common chest wall deformity with up to $80 \%$ of the cases occurring in male patients $[1,2]$. Most cases of PC are sporadic, however there seems to be a congenital or hereditary origin, as it can occur as part of a genetic disorder or syndrome (i.e., Ehlers-Danlos syndrome, Marfan syndrome, trisomy 18, homocystinuria or Morquio syndrome) [3]. Hereditary links are suggested by the observation of PC in monozygotic twins, by the neonatal presentation and by increased incidence of other chest wall abnormalities in family members [3]. Although there is no established etiology, an abnormal pattern of cartilage growth and metabolism is thought to be involved in its etiophatogenesis $[4,5]$. This condition is usually asymptomatic and rarely associated with respiratory symptoms [6]. The unaesthetic appearance of the deformity however, may have psychological impact leading to insecurity, decreased confidence and low self-esteem.

During the last half-century, the standard procedure in the correction of PC was the open approach involving costal cartilage resection,

\footnotetext{
* Corresponding author at: Escola de Ciências da Saúde, Universidade do Minho, Campus de Gualtar, 4710-057 Braga, Portugal. Tel.: + 351253604 910; fax: + 351253604 862.

E-mail address: jcp@ecsaude.uminho.pt (J. Correia-Pinto).
}

wide pectoralis muscle dissection and sternal osteotomy [7]. The application of pressure over the protruded chest wall using orthosis was a nonsurgical alternative proposed during the nineties, but this alternative is not always successful $[8,9]$. For these patients, minimally invasive surgical approaches have been proposed, following two main inspiring ideas: the correction of the thoracic malformation by compression of the sternum with a subcutaneous bar $[7,10]$ and the correction by costal cartilage resection $[11,12]$. Isolated cartilage resection may not be enough to correct bilateral and chondromanubrial deformities associated with sternal defects. However, multiple costal cartilage resections seem to be a good option for asymmetric unilateral PC avoiding the need for a bar and its subsequent removal reoperation [11,12]. Also in severe asymmetric PC, compressive techniques are not straightforwardly applied, as some patients are noncompliant.

Cartilage resection has been achieved either by thoracoscopic approach $[11,12]$ or by creating an epicostal space, that is, inflating $\mathrm{CO}_{2}$ under the pectoralis major muscle [13]. The number of reported cases is not large and, in the authors' knowledge, there is no previously published comparison between these two different strategies $[11,12]$.

Kim and Idowu's [11] and Varela and Torre's [12] thoracoscopic approaches differ from each other in the extent of cartilage resection; from Varela and Torre's point of view a more extensive cartilage resection may alter the need for postoperative external compression. However, 
a wider resection is not fully harmless; in order to reach the most medial portions of costal cartilages, obliteration of the internal thoracic vessels is required. This could be exceptionable because coronary heart disease is the worldwide leading cause of death and in selected patients coronary artery bypass graft will improve tremendously these patients outcome $[14,15,16,17]$. Graft patency is associated with long-term survival and left internal thoracic artery (ITA) graft has proved a higher rate of patency at 10 years $[18,19,20]$. Moreover, in multiple arteries bypass graft, right ITA might be the second best graft as it can further improve long-term survival and reduce adverse events [21].

Given the importance of internal thoracic arteries, this work aims to simulate and assess the feasibility of unilateral pectus carinatum repair with preservation of the internal thoracic vessels by resecting costal cartilages and compare thoracoscopic and subcutaneous (submuscular) endoscopic approaches.

\section{Materials and methods}

\subsection{Design}

Twelve pigs (Sus scrofus domesticus) weighing 25 to $35 \mathrm{~kg}$ were alternately assigned to a thoracoscopic group ( $\mathrm{T}$ ) and a subpectoralis group (SP), to avoid the effect of a learning curve. In T, 3rd to 5th costal cartilages were resected by thoracoscopy; whereas in SP, the same cartilages were resected by endoscopic approach with subpectoralis $\mathrm{CO}_{2}$ inflation.

Preservation of the internal thoracic vessels was attempted in both groups. The operative details, acute and postmortem outcomes were assessed and compared. This study was approved by the ethical review board of Minho University (Braga, Portugal).

\subsection{Pig preparation}

All procedures were performed under general anesthesia with endotracheal intubation and mechanical ventilation. Pigs were submitted to preoperative 8-hour food-fasting or 4-hour water-fasting. The animals were premedicated with a combination of azaperone $(4 \mathrm{mg} / \mathrm{kg}$, intramuscular), midazolam (1 $\mathrm{mg} / \mathrm{kg}$, intramuscular), and atropine ( $0.05 \mathrm{mg} / \mathrm{kg}$, intramuscular). Anesthesia was induced with propofol (6 mg/kg, intravenous) and maintained with continuous propofol infusion $(20 \mathrm{mg} / \mathrm{kg} / \mathrm{h}$, intravenous) and buprenorphine $(0.05 \mathrm{mg} / \mathrm{kg}$, intramuscular).

\subsection{Surgical technique}

In T (Video 1), the pig was placed in lateral decubitus. A $10 \mathrm{~mm}$ variable view angle endoscope (EndoCAMeleon ${ }^{\circledR}$ Hopkins ${ }^{\circledR}$, 26003AE, Karl Storz, Tuttlingen, Germany) was introduced through a $11 \mathrm{~mm}$ trocar (30123TPS, Karl Storz) located in the fifth intercostal space (ICS) in

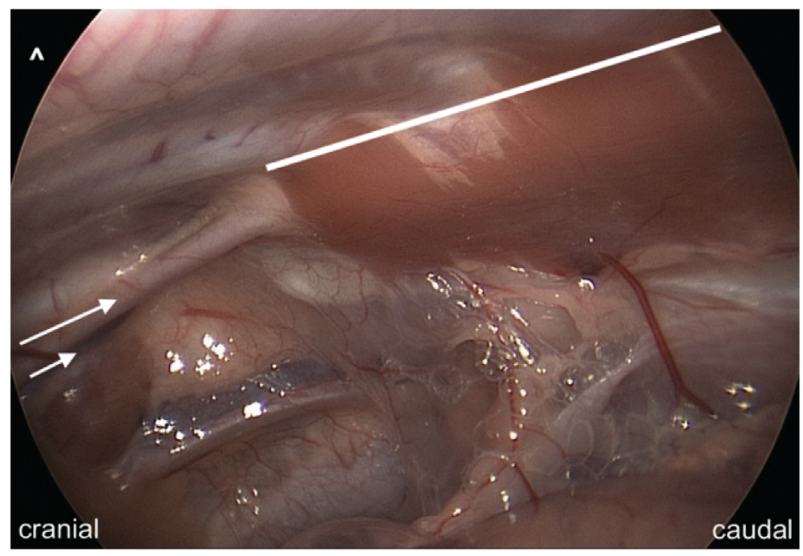

Fig. 2. Thoracoscopic operative view: long arrow-right internal thoracic artery; short arrow-right internal thoracic vein; line-lateral insertion of right transverse thoracic muscle, sectioned for caudal preservation the vessels; the arrow head marks what is anterior.

the posterior axillary line. The capnothorax was established with an inflation rate of $1 \mathrm{~L} / \mathrm{min}$ and maintained with a pressure up to $6 \mathrm{~mm} \mathrm{Hg}$. Two additional $5 \mathrm{~mm}$ working ports (30120TRX, Karl Storz) were placed in the forth ICS (posteriorly) and sixth ICS (anteriorly to the telescope trocar) as shown in Fig. 1A. Using a $5 \mathrm{~mm}$ grasping forceps (CLICK'line, 33310ML, Karl Storz) and the hook (Cadiere Monopolar Dissecting L-shaped Electrode, 26775CL, Karl Storz), the lateral insertion of the transverse thoracic muscle was sectioned (Fig. 2). The internal thoracic vessels are then identified, isolated and pushed away from the costal cartilage (medially and posteriorly); special care was taken to coagulate small braches (mediastinal, sternal and perforating branches) to prevent bleeding. With combined use of monopolar hook, endoscopic $45^{\circ}$ rongeur (Medtronic Sofamor-Danek, Memphis, TN, USA) and endoscopic perichondrium elevator (Medtronic Sofamor-Danek, Memphis, TN, USA) the perichondrium was opened and 3rd, 4th and 5th costal cartilages were almost totally resected, leaving cartilage stumps of less than a centimeter.

In SP (Video 2), the pig was placed in lateral position. A $10 \mathrm{~mm}$ incision was made in the posterior axillary line (Fig. 1B) and a working space was created beneath the pectoralis major muscle using forceps. An $11 \mathrm{~mm}$ trocar (30123TPS, Karl Storz) was introduced and the $\mathrm{CO}_{2}$ inflated with a pressure up to $18 \mathrm{~mm} \mathrm{Hg}$ and inflation rate up to $5 \mathrm{~L} / \mathrm{min}$. As in T, the same endoscope was introduced and two additional $5 \mathrm{~mm}$ working-ports (30120TRX, Karl Storz) were placed under visualization. Further dissection was performed toward the midline and special caution was needed to promptly coagulate any perforating branches of the internal thoracic vessels. The same instruments were used as in $\mathrm{T}$. The pectoralis major, rectus abdominis and serratus anterior muscles were bluntly dissected and eventually cut. The perichondrium was opened and cartilage resected using monopolar hook and the
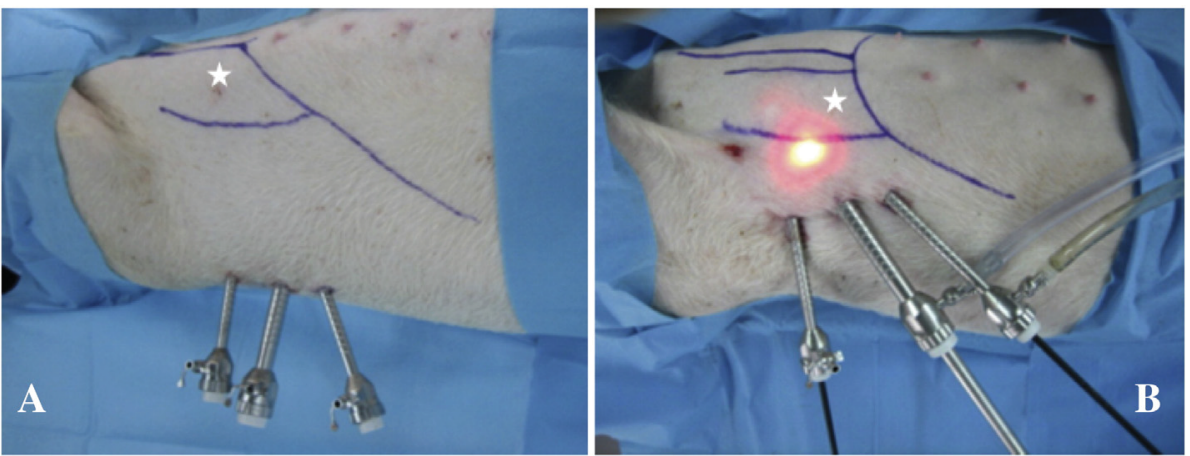

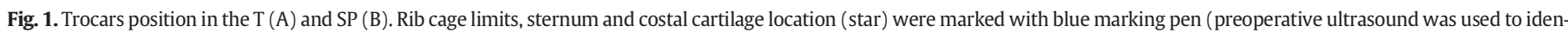
tify the cartilage/bone transition). 
Table 1

Modified GRITS index: 6 items visual analog scale [22].

\begin{tabular}{|c|c|c|}
\hline 2 & 3 & 5 \\
\hline $\begin{array}{l}\text { 1. Respect for tissue } \\
\text { Frequent unnecessary force on tissue, damage by } \\
\text { inappropriate use of instruments }\end{array}$ & $\begin{array}{l}\text { Careful handling of tissue with occasional } \\
\text { inadvertent damage }\end{array}$ & $\begin{array}{l}\text { Consistent appropriate handling } \\
\text { of tissue with minimal tissue damage }\end{array}$ \\
\hline $\begin{array}{l}\text { 2. Time and motions } \\
\text { Many unnecessary movements }\end{array}$ & $\begin{array}{l}\text { Efficient time and motion but some unnecessary } \\
\text { movements }\end{array}$ & $\begin{array}{l}\text { Clear economy of movement and } \\
\text { maximum efficiency }\end{array}$ \\
\hline $\begin{array}{l}\text { 3. Instrument handling } \\
\text { Tentative/awkward moves }\end{array}$ & Occasionally awkward & $\begin{array}{l}\text { Fluid moves with instruments, no } \\
\text { awkwardness }\end{array}$ \\
\hline $\begin{array}{l}\text { 4. Flow of operation } \\
\text { Frequently stopped }\end{array}$ & Reasonable progression & Effortless flow \\
\hline $\begin{array}{l}\text { 5. Instrument conflict } \\
\text { Reduced image quality or impaired movements } \\
\text { caused by instrument conflict }\end{array}$ & Few telescope/instruments conflict & No instruments conflict \\
\hline $\begin{array}{l}\text { 6. Visibility and image quality } \\
\text { Frequent stops caused by image quality impairment } \\
\text { and awkward view of working field with useless } \\
\text { image angles }\end{array}$ & $\begin{array}{l}\text { Fair image quality, inadequate working field view } \\
\text { or perspective angles }\end{array}$ & $\begin{array}{l}\text { Perfect image quality and visualization } \\
\text { of working field, optimized view angles }\end{array}$ \\
\hline
\end{tabular}

endoscopic rongeur. Special care was taken to prevent rupture the posterior perichondrium and ultimately entering the thoracic cavity.

\subsection{Main outcome measurements}

Perioperative details were recorded, including operative time, feasibility, safety, internal thoracic vessels preservations, injuries and surgical difficulty.

In order to assess the global intraoperative difficulties a modified version of a previous validated index was used: GRITS-Global Rating Index for Technical Skills. This index is not procedure specific and can be applied to a variety of surgeries [22]. Our diagram evaluates the difficulty of the operation with six Likert scale items. The first four are equivalent to the original GRITS table and the last two (instrument conflict, visibility and image quality) were added, replacing incompatible items. As in the original GRITS, each domain is scored from 1 to 5 with anchor descriptors for 1,3 , and 5 scores (Table 1). Two external observers, the surgeon and the assistant evaluated each procedure according to this modified GRITS index. The interrater reliability was measured using the Spearman's rank correlation coefficient. GRITS scores were compared using Student $t$ test.

At the end of surgery, ITV was checked for patency with regular Doppler ultrasound as in Fig. 3 (Vivid3, General Electric, Connecticut, USA with $12 \mathrm{~L}$ probe [4-11 $\mathrm{mHz}]$ ). The animal was then sacrificed with an overdose of pentobarbital $(100-150 \mathrm{mg} / \mathrm{kg}$ ) following the guidelines of animal experimentation [23] and ITV integrity and patency was confirmed by the methylene blue test. This test consisted in the injection of both vessels (artery and vein) with methylene blue; the vessels were considered "preserved" when the abdominal wall acquired a blue coloration (Fig. 4) and no perivascular leaks were noticed.

\section{Results}

The procedure was safely completed and preservation of the ITA was accomplished in all animals from both groups. ITA patency and flux were confirmed by Doppler-ultrasound (Fig. 3) and the methylene blue test in every case (Fig. 4). The operative data are presented in Table 2. The surgical procedure was significantly quicker in the T group ( $49 \pm 5$ versus $65 \pm 16$ minutes, $p<0.05$ ).

In the T group, two cases presented with lung adhesions; these were initially divided using monopolar hook and the surgery proceeded with no additional difficulties. In the remaining pigs there were no complications or relevant difficulties.

In the SP group, there was the need for muscle section in order to reach the costal cartilage. The serratus anterior and the rectus abdominis have costal and sternal insertions that ultimately required to be divided. In one animal, the pleural cavity was opened during this process. The pleural opening induced an iatrogenic capnothorax and did not permit to maintain high $\mathrm{CO}_{2}$ inflation pressures. Even with lower inflation pressures, our team struggled to sustain adequate ventilation and this was the cause of frequent time-consuming stops. Nevertheless, resection was accomplished in this case (Table 2). At the end of the surgery, there was significant subcutaneous thoracoabdominal emphysema in all SP pigs, as shown in Fig. 5.

Regarding the reliability of the modified GRITS, there was a significant interrater reliability with an average level of agreement $(\rho)$ of
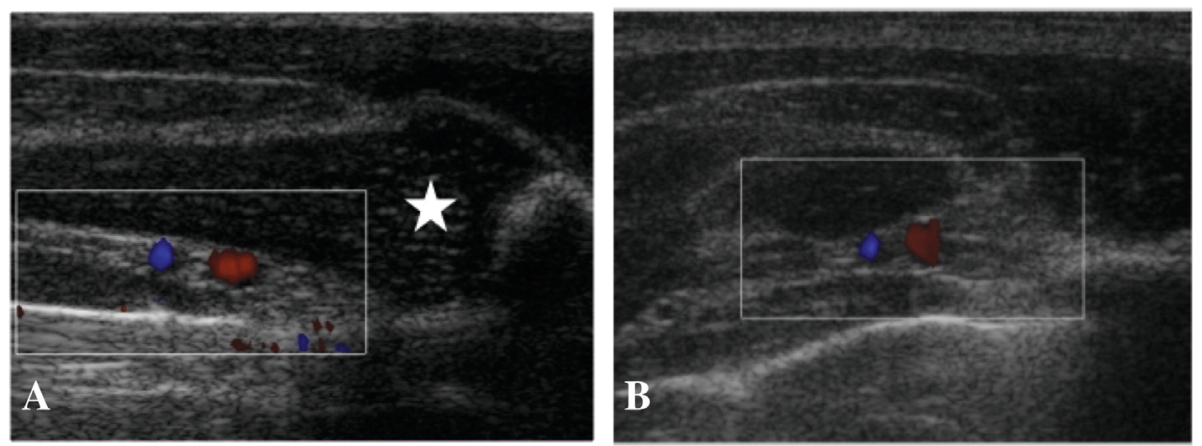

Fig. 3. Doppler ultrasound: before (A) with costal cartilage (arrow) and after the procedure (B). The internal thoracic artery is blue-colored; the internal thoracic vein is red-colored. 


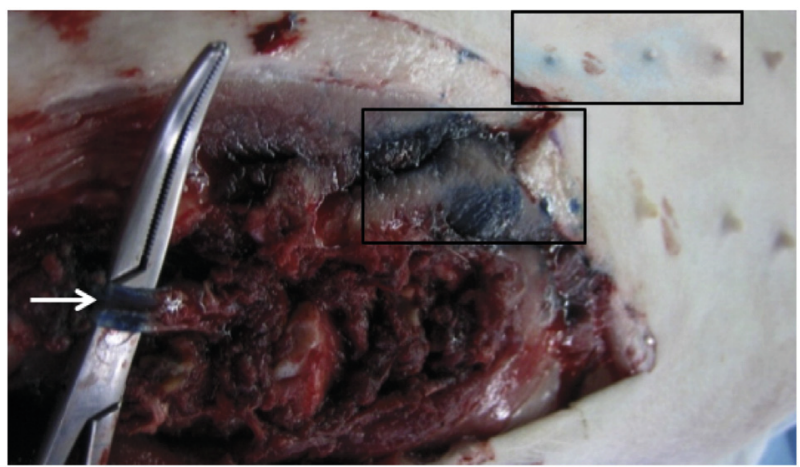

Fig. 4. Methylene blue test: after injection of the dye and no leakage (arrow). Note the highlighted perfusion territories of the ITA (blue coloration of the muscles and skin).

0.328 (with only one exception, each possible pair had a two-tailed $p$ value lower than 0.05 ).

The observers, the surgeon and the assistant classified the $\mathrm{T}$ as easier than SP with a mean overall index of 4.2 versus 3.3 , respectively $(p<0.001)$ and giving higher scores for all items in T. The difference was more significant regarding visibility and image quality (4.4 versus $3.1, p<0.001$ ) and with respect to tissue ( 4 versus $2.6, p<0.001$ ). The modified GRITS data are summarized in Table 3.

\section{Discussion and conclusions}

Chest wall protrusions are classified in two main forms: chondromanubrial or chondrogladiolar pectus carinatum. Additionally, it can be described as symmetrical or asymmetrical, according to the bilateral or unilateral position of the protrusion [3]. Often this condition is totally asymptomatic but there may be associated symptoms. As the reported physiologic studies in PC patients are sparse, the association of PC and respiratory dysfunction is controversial. Nevertheless, PC may result in psychological difficulties and limitations. Usually these are introvert patients refraining from social activities in which their chest could be exposed, developing insecurity and reducing confidence and self-esteem. As the functional impact of the surgery is doubtful, most authors' main indication is based on cosmesis, with purpose to improve quality of life $[6,24,25]$.

The best treatment of PC deformities is still debated and investigated. The classic operation is an aggressive open surgery; as there were no minimally invasive solutions and there are no clear surgical indications, PC was named the "undertreated chest deformity" [6,7]. In the last decades, compression of the protruded thoracic deformity using an orthosis was a breakthrough. However it requires long-term adhesion and the lack of immediate effects potentially leads to noncompliance $[8,9]$.

For asymmetric unilateral PC multiple costal cartilage resections have been reported with no need for bar use or its subsequent removal reoperation $[11,12,13]$. In the previously reported techniques it was not always possible to preserve the internal thoracic vessels (ITV). The issue

Table 2

Operative data.

\begin{tabular}{|c|c|c|c|c|c|c|c|c|}
\hline & $\mathrm{T}$ & & & & SP & & & \\
\hline Experiment & 135 & 7 & 9 & 11 & 2 & 8 & 10 & 12 \\
\hline ITV preservation & $\swarrow$ & & & & $\mathscr{\swarrow}$ & & & \\
\hline Muscle resection & Minor (Trasve & ersus & thora & & $\begin{array}{l}\text { Major (Pecto } \\
\text { rectusabdom } \\
\text { serratusante }\end{array}$ & $\begin{array}{l}\text { ralis } \\
\text { inis, } \\
\text { ior) }\end{array}$ & major & \\
\hline Subcutaneous emphysema & No & & & & Yes & & & \\
\hline Operative time (min) & $\begin{array}{lll}53 & 47 & 41\end{array}$ & 56 & 52 & 43 & $84 \quad 53 \quad 57$ & 66 & $86^{\mathrm{a}}$ & 43 \\
\hline Mean operative time (min) & $49 \pm 6$ & & & & $65 \pm 15.5$ & & & \\
\hline
\end{tabular}

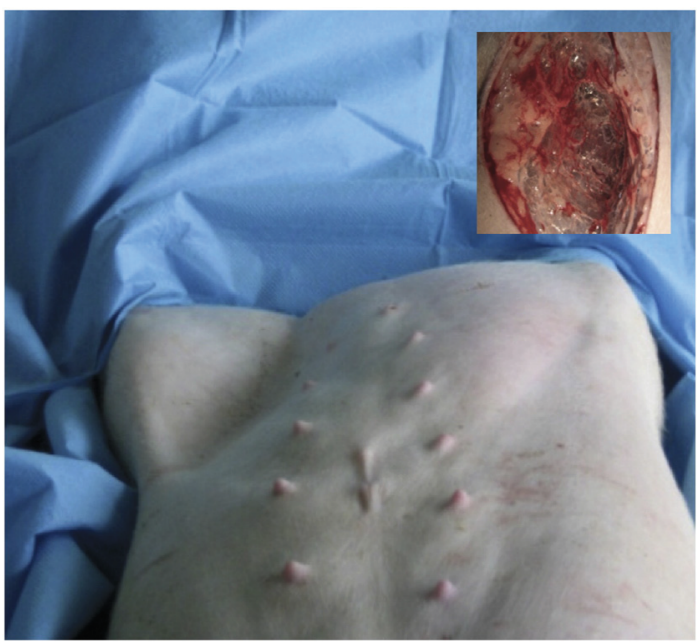

Fig. 5. Subcutaneous emphysema.

of ITV preservation and patency has also been raised in the correction of pectus excavatum using the Nuss procedure, in which there seems to be the frequent collapse of ITV. However, there are no clear data regarding the patency after the removal of the bar $[26,27]$.

Pediatric thoracic surgeons should bear in mind that coronary heart disease is the worldwide leading cause of death and coronary artery bypass graft may improve the outcome $[14,15,16,17,28]$. Saphenous vein grafts have a patency rate of $60 \%$ at 10 years, while patency rates for left internal thoracic artery (ITA) at 10 years are as high as $98 \%$ $[18,19,20]$. Graft patency is associated with a long-term survival and an attempt is made to place at least one arterial graft. Combined use of multiple arterial grafts (two or more) has a better long-term survival and the second best graft after the left ITA is the right ITA $[18,19,20,21,29,30]$. It might be questionable to correct a deformity with such a strong male predominance, in detriment of the potentially therapeutic value of both internal thoracic arteries in coronary artery disease. Our work has proven that sparing the ITV during cartilage resection for correction of unilateral PC is feasible in a porcine model. In the thoracoscopic approach, even though we performed wide cartilage resections, ITV preservation was feasible by dissecting, coagulating small branches and pulling away the vessels.

There are two described options for the cartilage resection: by dissecting under the pectoralis major muscle and inflating the neo-cavity with $\mathrm{CO}_{2}$ and by thoracoscopic approach $[11,12,13]$. There were no previous studies comparing the two approaches and few cases have been reported $[11,12,13]$. Based on our findings, the thoracoscopic approach (T) was quicker and seems to be a more "muscle sparing" technique; in SP there was the inevitable need to cut muscle fibers in order to reach the cartilages, as the muscles are actually inserted over the cartilage. There is also the risk to perforate into the chest cavity, which occurred in one case and made the surgery more difficult, but not impossible, or life threatening. The authors were also concerned about the substantial subcutaneous emphysema extending caudally to the pelvic region observed in all SP cases. One possibility is that too high

Table 3

GRITS score.

\begin{tabular}{lrrr}
\hline Median values (range) & \multicolumn{1}{l}{ T } & \multicolumn{1}{l}{ SP } & \\
\hline Respect for tissue & $4(3-5)$ & $3(1-4)$ & $p<0.05$ \\
Time and motion & $4(3-5)$ & $3(3-4)$ & $p<0.05$ \\
Instrument handling & $4(2-5)$ & $4(2-4)$ & $p<0.05$ \\
Flow of operation & $4.5(3-5)$ & $4(1-5)$ & $p<0.05$ \\
Instrument conflict & $4(3-5)$ & $3.5(1-5)$ & $p<0.05$ \\
Visibility and image quality & $5(3-5)$ & $3(2-5)$ & $p<0.05$ \\
Overall score & $4(2-5)$ & $3(1-5)$ & $p<0.05$ \\
\hline
\end{tabular}


$\mathrm{CO}_{2}$ pressures were used (18 $\mathrm{mm} \mathrm{Hg}$ versus $15 \mathrm{~mm} \mathrm{Hg}$ reported by Schaarschmidt $[13,31])$ and this issue might be addressed only by lowering the pressure, otherwise the SP could be associated with significant morbidity. There are no reported data regarding this possible complication, and the only stated concern was a moderate rise in systemic $\mathrm{CO}_{2}[13,31]$. Although more than three costal cartilages can be resected by thoracoscopy, sternal osteotomy might be difficult and risky, whereas in previous studies, it was possible to perform more aggressive surgical techniques using the subpectoralis approach, including sternal osteotomies to repair sternal deformities [13,31].

The two approaches were also compared regarding their difficulty, using a modified version of the previously validated GRITS. The new index proved to be very consistent despite any modification, as there was a significant interrater reliability with an average level of agreement $(\rho)$ of 0.328 (near all possible pairs had a two-tailed $p$ value lower than 0.05). The GRITS data show that thoracoscopy is the easiest approach: there was less instrument conflict and more appropriate handling of the tissues, resulting in more efficiency and less awkward movements with a better flow of the operation. Additionally, there was better image quality with better visualization of the working field by optimized view angles (Table 3 ). The authors believe that the major muscle sections in SP, represented a worst tissue handling, were time-consuming and ultimately impaired the image quality because of the smoke being released during the frequent cautery use.

Using a porcine model it was possible to recreate and simulate the same surgical steps required for costal cartilage resection, but the authors recognize the limitation of a nonsurvival animal study. It was not possible to access the outcomes based on esthetic results or improvements in quality of live, and those are probably the main goals of the procedure [25]. Therefore it may be difficult to extrapolate which approach will have better outcomes in the real world, however the preservation of the ITV should be a milestone.

In conclusion, this work shows that there is no need to sacrifice the ITA to resect costal cartilages and hopes to make surgeons aware of this issue. Thoracoscopic approach is efficient, faster and easier, offers a better image quality and requires less muscle damage than subcutaneous approach.

Supplementary data to this article can be found online at http://dx. doi.org/10.1016/j.jpedsurg.2015.07.023.

\section{References}

[1] Robicsek F, Daugherty HK, Mullen DC, et al. Technical considerations in the surgical management of pectus excavatum and carinatum. Ann Thorac Surg 1974;18: 549-64.

[2] Lester CW. Pigeon breast (pectus carinatum) and other protrusion deformities of the chest of developmental origin. Ann Surg 1953;137:482-9.

[3] Coelho M, Guimarães P. Pectus carinatum. J Bras Pneumol 2007;33:463-74.

[4] Brochhausen C, Müller FKP, Turial S, et al. Pectus carinatum-first ultrastructural findings of a potential metabolic lesion. Eur J Cardiothorac Surg 2012;41:705-6.

[5] Park CH, Kim TH, Haam SJ, et al. The etiology of pectus carinatum involves overgrowth of costal cartilage and undergrowth of ribs. J Pediatr Surg 2014;49:1252-8.

[6] Fonkalsrud EW, Anselmo DM. Less extensive techniques for repair of pectus carinatum: the undertreated chest deformity. J Am Coll Surg 2004;198:898-905.
[7] Abramson H, D'Agostino J, Wuscovi S. A 5-year experience with a minimally invasive technique for pectus carinatum repair. J Pediatr Surg 2009;44:118-23 [discussion 123-114].

[8] Haje SA, Bowen JR. Preliminary results of orthotic treatment of pectus deformities in children and adolescents. J Pediatr Orthop 1992;12:795-800.

[9] Vidal J, NG. Tratamiento ortopédico de las deformaciones torácica. In: Villadot R, CO, Clavell S, editors. Ortesis y prótesis del aparato locomotor: Columna vertebral. Barcelona: Masson; 1994. p. 85-93.

[10] Kalman A. Initial results with minimally invasive repair of pectus carinatum. J Thorac Cardiovasc Surg 2009;138:434-8.

[11] Kim S, Idowu O. Minimally invasive thoracoscopic repair of unilateral pectus carinatum. J Pediatr Surg 2009;44:471-4.

[12] Varela P, Torre M. Thoracoscopic cartilage resection with partial perichondrium preservation in unilateral pectus carinatum: preliminary results. J Pediatr Surg 2011;46:263-6.

[13] Schaarschmidt K, Kolberg-Schwerdt A, Lempe M, et al. New endoscopic minimal access pectus carinatum repair using subpectoral carbon dioxide. Ann Thorac Surg 2006;81:1099-103.

[14] Murphy S, Xu J, Kochanek K. Deaths: final data for 2009. National Vital Statistics Reports, 60; 2013.

[15] Lloyd-Jones D, Adams RJ, Brown TM, et al. Executive summary: heart disease and stroke statistics-2010 update: a report from the American Heart Association. Circulation 2010;121:948-54.

[16] Rosamond W, Flegal K, Friday G, et al. Heart disease and stroke statistics-2007 update: a report from the American Heart Association Statistics Committee and Stroke Statistics Subcommittee. Circulation 2007;115:e69-171.

[17] Moscarelli M, Harling L, Attaran S, et al. Surgical revascularisation of the acute coronary artery syndrome. Expert Rev Cardiovasc Ther; 2014.

[18] Ferguson Jr TB, Coombs LP, Peterson ED. Internal thoracic artery grafting in the elderly patient undergoing coronary artery bypass grafting: room for process improvement? J Thorac Cardiovasc Surg 2002;123:869-80.

[19] Leavitt BJ, O'Connor GT, Olmstead EM, et al. Use of the internal mammary artery graft and in-hospital mortality and other adverse outcomes associated with coronary artery bypass surgery. Circulation 2001;103:507-12.

[20] Mehta RH, Ferguson TB, Lopes RD, et al. Saphenous vein grafts with multiple versus single distal targets in patients undergoing coronary artery bypass surgery: one-year graft failure and five-year outcomes from the Project of Ex-Vivo Vein Graft Engineering via Transfection (PREVENT) IV trial. Circulation 2011;124:280-8.

[21] Ruttmann E, Fischler N, Sakic A, et al. Second internal thoracic artery versus radial artery in coronary artery bypass grafting: a long-term, propensity score-matched follow-up study. Circulation 2011;124:1321-9.

[22] Doyle JD, Webber EM, Sidhu RS. A universal global rating scale for the evaluation of technical skills in the operating room. Am J Surg 2007;193:551-5 [discussion 555].

[23] Zutphen LFMv, Baumans V, Beynen AC. Principles of laboratory animal science: a contribution to the humane use and care of animals and to the quality of experimental results. Amsterdam; New York: Elsevier; 2001.

[24] Fonkalsrud EW. Surgical correction of pectus carinatum: lessons learned from 260 patients. J Pediatr Surg 2008;43:1235-43.

[25] Pessanha I, Severo M, Correia-Pinto J, et al. Pectus Carinatum Evaluation Questionnaire (PCEQ): a novel tool to improve the follow-up in patients treated with brace compression. Eur J Cardiothorac Surg 2015 [pii: ezv198, Epub ahead of print].

[26] Kulcu K, Elenbaas TW, Nguyen DT, et al. Patency of the internal mammary arteries after removal of the Nuss bar: an initial report. Interact Cardiovasc Thorac Surg 2014;19:6-9.

[27] Yuksel M, Ozalper MH, Bostanci K, et al. Do Nuss bars compromise the blood flow of the internal mammary arteries? Interact Cardiovasc Thorac Surg 2013;17:571-5.

[28] Lozano R, Naghavi M, Foreman K, et al. Global and regional mortality from 235 causes of death for 20 age groups in 1990 and 2010: a systematic analysis for the Global Burden of Disease Study 2010. Lancet 2012;380:2095-128.

[29] Lytle BW, Blackstone EH, Sabik JF, et al. The effect of bilateral internal thoracic artery grafting on survival during 20 postoperative years. Ann Thorac Surg 2004;78: 2005-12 [discussion 2012-2004]

[30] Zacharias A, Habib RH, Schwann TA, et al. Improved survival with radial artery versus vein conduits in coronary bypass surgery with left internal thoracic artery to left anterior descending artery grafting. Circulation 2004;109:1489-96.

[31] Schaarschmidt K, Lempe-Sellin M, Schlesinger F, et al. New Berlin-Buch "reversed Nuss," endoscopic pectus carinatum repair using eight-hole stabilizers, submuscular $\mathrm{CO}_{2}$, and presternal Nuss bar compression: first results in 35 patients. J Laparoendosc Adv Surg Tech A 2011;21:283-6. 